\title{
BIODEGRADAÇÃO DE RESÍDUOS ORGÂNICOS NO SOLO
}

\author{
SÂ MIA MARIA TAUK*
}

\begin{abstract}
BIODEGRADATION OF ORGANIC RESIDUES IN SOIL. Biodegradation is a complex and multifacited process involving an enormous nmnber and variety of soil organisms. Four groups of microorganisms OCCUR during the decomposition of vegetal residues: cellutolytics, nemicellulolytics pectinolytics and ligninolytics, with exception of the anaerobics and chimiotrophics organisms, these have large energy demands. The study of biodegradation does not require complex methods, but does require long time intervals and is labor intensive. During the decomposition of leaf litther in a "cerrado sensu stricto" area me most frequent filamentous fungi Were: TMchoderma, AbsUBa, fusariam and CyündrodacKum. The addition of organic residue can change the litter decomposition rate.
\end{abstract}

Keywords: Filamentous range, "cerrado".

RESUMO A biodegradaçfo 6 um processo complexo que envolve grande número e variedade de microrganismos na decomposiçio de material vegetal. Existem peto menos quatro grupos distintos desses organismos: celulolíticos, hemkelulolfticos, pectinolftícos e Hgninolíticos, que necessitam de muita energia, exceto os casos de anaeróbios e qumüotíofkos. Nem sempre o estudo da btodegradaçSo exige metodologia complicada, entretanto, é trabalhosa e muitas vezes demorada. Durante a decomposição de folhedo da área de cerrado sensu stricto, os fungos filamentosos mais freqüentes foram Trichodema, Abstâa. Fusarium e CyBndrookuOum. A adiçjto de um resíduo orgânico altera a velocidade de decomposição do folhedo no solo. Algumas proposições de estudos futuros sSo colocadas.

Palavras-chaves: Fungos filamentosos, cerrado.

INTRODUÇÃO A decomposição de resíduos orgânicos pode ser determinada diretamente pela perda de peso ou por técnicas que utilizem elementos marcados, demonstrando que no final do processo há liberação de CCfe, formação de nova biomassa e metabolites, e de materiais resistentes a degradação.

No solo ocorre rápida decomposição inicial de material lábil e, posteriormente, num processo mais lento, de materiais mais resistentes. Essa lentidão pode ocorrer devido ao mecanismo de adsorção, à estabilização de metabolites e à queda da taxa de biomassa no solo. Enfim, a biodegradação é um processo complexo e multifacetado, envolvendo grande número e variedade de microrganismos do solo.

A degradação de diferentes resíduos depende das condições locais e regionais como clima, tipo de solo, vegetação, fauna e microrganismos decompositores. A diversidade bioquímica de substratos macromoleculares indica que os organismos devem possuir amplo espectro de enzimas extracelulares para convertê-los em metabolites assimiláveis. As propriedades do solo, tais como, argila, $\mathrm{pH}$, matéria orgânica, tensão de água e aeração atuam como fatores ambientais do processo de decomposição.

Assim, a complexidade física e química dos resíduos orgânicos desfavorece a ocorrência de um processo degradativo biologicamente simples. As paredes das células vegetais, por exemplo, são compostas de uma intrincada rede de fibras de celulose juntamente com a pectina heteropolimérica, hemicelulose e, em tecidos maduros, lignina. Além disso, os tecidos vegetais freqüentemente possuem uma cutícula protetora de gomas e ceras, podendo conter ainda compostos antimicrobianos que podem inibir a ação de certas enzimas degradativas.

COMPOSIÇÃO QUÍMICA Entre 50\% e 80\% da matéria seca dos vegetais é carboidrato, enquanto os microrganismos contêm até $60 \%$ de C orgânico. A quantidade e proporção deste elemento na célula, tecidos ou organismos inteiros são determinadas pelas espécies e idade dos indivíduos. Por exemplo, embora os carboidratos solúveis em água possam predominar em plantas jovens, as maduras têm maior porcentagem de celulose, hemicelulose e lignina.
De modo geral, a matéria orgânica vegetal é constituída dei celulose, mais abundante polímero, compreendendo $40 \%$ a $60 \%$ do lenho maduro, $10 \%$ das folhas, $30 \%$ a $40 \%$ do caule e $90 \%$ das fibras de algodão; hemicelulose, grupo diverso de polissacarídeos solúveis em álcalis, intimamente associado à celulose; substâncias pecticas, polissacarídeos estruturais e lignina, importante composto de carbono constituinte de plantas vasculares, participando com $15 \%$ a $34 \%$ da madeira.

Os tecidos animais geralmente contêm menor proporção de carboidratos em relação aos vegetais e microrganismos. A quitina, contudo, é um importante componente orgânico dos artrópodes. $\mathrm{O}$ gǗcogênio tem estrutura e função similares às do amido e um grande número de carboidratos animais ocorrem como glicoprotemas.

Os constituintes orgânicos microbianos compreendem: a quitina, superada somente pela celulose em abundância; as quitosanas, que ocorrem nas paredes de bifas de fungos zigomicetos como o Mucor, Mortiereüa e Rhizopus; o peptideoglucam, polímero estrutural, de praticamente todas as paredes bacterianas, contribuindo de $5 \%$ a $10 \%$ em Escheria coti e de ate' $60 \%$ a $70 \%$ em Micrococcus luteus da matéria seca da parede celular, os lipopolissacarídeos, que formam parte da membrana externa de bactérias Gram-negativas e representam $20 \%$ a $30 \%$ da massa seca da parede celular, os ácidos tecóicos e teicurônicos, componentes da parede celular de bactérias Gram-positivas e os exopolissacarídeos, produzidos por microrganismos do solo, Pseudamonas, Xanthomonas, Bacillus, Azotobacter, RMbobium e Arthrobacter.

Os ácidos húmicos, que constituem a reserva de matéria orgânica do solo, parecem ser constituídos de polímeros complexos de hidroxi-fenóis, ácidos hidroxibenzóicos e outras substâncias aromáticas, ligadas a peptfdeos, compostos aminoaçúcares, ácidos graxos, parede celular e fragmento protoplasmático microbiano, e possivelmente outros constituintes. A capacidade de vários compostos fenólicos sofrerem reações enzimáticas e polimerização auto-oxidativas, é provavelmente de grande importância na formação de moléculas de ácidos húmicos. Estruturas condensadas de anéis aromáticos e partes de lignina e moléculas de melanina podem também integrar as moléculas do polímero húmico. A simples hidrólise ácida 
liberará aminoácidos peptfdeos e açúcares de unidades polissacarídicas, associadas com ácidos húmicos.

Metflação e oxidação dos ácidos húmicos com permanganato ou oxido de cobre $(u)$ formam uma série de ácidos carboxflicos di-, tri-, tetra-, penta- e hexabenzeno, fenóis e ácidos graxos. A degradação de ácidos húmicos por amálgama de sódio produz aproximadamente de $15 \%$ a $35 \%$ de material éter solúvel e grande variedade de substâncias fenólicas simples. Estudos têm demonstrado que esses fenóis, produzidos por essa degradação, são os mesmos que aqueles utilizados para sintetizar o polímero ou compostos levemente alterados, formados por decarboxilação ou migração de um grupo hidroxila para outro anel de benzeno por meio de ligação éter-anel.

Uma grande parte dos estudos da biodegradação, envolvendo resíduos marcados ou não com carbono, mostrou que a maior porcentagem desse elemento é liberada como $\mathrm{CO}_{2}$ e que a quantidade estabilizada do novo húmus não é significativamente influenciada por adições de até $2 \%$ do substrato. Foi demonstrado que a quantidade de húmus, o pH e a cobertura vegetal exercem pouca influência sobre o teor total de carbono orgânico estabilizado.

A quantidade e o tipo de argila podem afetar, entretanto, grandemente o local de carbono orgânico estabilizado. Assim, para a celulose, as argilas podem com freqüência aumentar a taxa de crescimento microbiano, especialmente durante a degradação inicial de substratos prontamente disponíveis, mas poderão reduzir a perda de carbono na forma de $\mathrm{CO}_{2}$ por aumentar a eficiência da utilização desse elemento pelos microrganismos e por formar complexos com produtos de decomposição e com substâncias húmicas.

A comparação da perda de carbono de muitos substratos orgânicos prontamente degradáveis, em solos agrícolas comuns do Chile e da Califórnia, demonstrou que a presença de argilas alofanas reduziu as perdas de carbono da maioria dos substratos e que essa redução foi acentuada quando se utilizou substrato com polímeros mais resistentes, como ligninas vegetais e melaninas de fungos em solos alofânicos.

Técnicas com isótopos demonstraram as influências de um tipo de substrato orgânico na decomposição de um outro, ou do húmus já presente no solo. Em uma série de experimentos, notou-se que a aplicação no solo de dois substratos prontamente disponíveis, um marcado com carbono e o outro não, decompuseram-se com a mesma velocidade de que quando aplicados individualmente. Foi sugerido que a adição de um substrato orgânico, prontamente degradável, pode aumentar grandemente a liberação de $\mathrm{CO}_{2}$ do húmus do solo.

Vários pesquisadores têm tentado preparar modelos para polímeros de ácidos húmicos na tentativa de entender melhor os possíveis mecanismos de formação, a natureza e propriedades dos mesmos. Substâncias fenólicas são fontes importantes na formação de polímeros de ácidos húmicos, já que numerosos defensivos agrícolas e outros produtos orgânicos sintéticos contêm porções de anéis benzênicos. De forma semelhante à que ocorre com os substratos orgânicos naturais, é necessário introduzir grupos hidroxila na porção benzênica para promover a ruptura destes compostos. Neste estágio, os compostos aromáticos podem ser polimerizados de modo oxidativo e integrados às moléculas de húmus, ou sofrer ruptura do. anel. Deve-se esperar, portanto, que a degradação parcial de compostos organo-fenólicos fabricados pelo homem integrem-se aos polímeros do humus do solo.

Recentemente, vários investigadores têm expressado o conceito de que os resíduos de defensivos agrícolas ou produtos tóxicos de decomposição parcial podem ser estabilizados no humu do solo e, posteriormente, liberados e absorvidos por microrganismos, mesofauna ou por plantas, e por isso, constituírem problema sério de poluição ambiental, o que é extremamente indesejável.
METODOLOGIA Para estudar a biodegradação no solo é preciso considerar a amostragem, que por sua vez, deverá ser estabelecida pela biologia do mesmo, local, tempo, estação, variações na textura, umidade, $\mathrm{pH}$, temperatura, acúmulo de serapilheira e associações que ocorrem na rizosfera.

Nem sempre o estudo da biodegradação exige metodologia complicada, entretanto é trabalhosa e muitas vezes demorada. O fluxo de nutrientes pode ser estudado pela produção e decomposição da serapilheira em um determinado ecossistema, entretanto, observa-se a necessidade desses estudos serem efetuados durante alguns anos. As altas concentrações de nutrientes minerais existentes no folhedo podem indicar que a fitocenose não dispõe de mecanismos especiais de conservação para esses elementos essenciais, quer em mata mesófila semidescídua quer em ecossistemas amazônicos. Elementos como o $\mathrm{K}, \mathrm{Mg}, \mathrm{S}$ e B são ciclados mais rapidamente do que os demais, por serem lixiviados com maior facilidade pela água da chuva, permanecendo assim um tempo menor no folhedo (Pagano 1985). Também em uma mata mesófila semidescídua no Estado de São Paulo, verificou-se que a quantidade total estimada de macronutrientes devolvidos no solo, anualmente, por meio da serapilheira, foi de $400,32 \mathrm{~kg} / \mathrm{ha}$ e a seqüência de participação, em ordem decrescente, foi a seguinte: $\mathrm{N}, \mathrm{Ca}, \mathrm{K}, \mathrm{Mg}, \mathrm{S}$ e P (César 1988).

MICROBIOLOGIA Embora aqui estejam enfatizados os aspectos microbianos da degradação, não há dúvidas quanto a importância da fauna do solo, especialmente os nematóides , anélidas e artrópodas, nos estágios iniciais da decomposição. A ação desses animais dá-se pela formação de galerias no solo, aumentando a área de exposição, aeração, difusão de inóculo ou pela redução do tamanho dos resíduos e pela digestão, facilitando a incorporação dos mesmos no solo.

A decomposição de material vegetal exógeno envolve pelo menos quatro grupos distintos de microrganismos: celulolíticos, hemicelulolíticos, pectinolíticos e ligninolíticos. Geralmente a degradação de um substrato complexo, folhas, tecidos microbianos mortos ou exoesqueletos de insetos processa-se mais rapidamente na presença de uma comunidade microbiana do que na presença de uma única população.

Muitos microrganismos do solo, fungos, bactérias e actinomicetos sintetizam melaninas e podem secrètá-las ou retêlas em suas células ou esporos. As melaninas de Epicoccwn nigrum, Aspergülus sydowi, Hendersoruda tondoidea e Eurotiwn echinulatum são similares aos ácidos húmicos quanto à composição elementar, elevada acidèz, liberação de aminoácidos via hidrólise ácida, liberação de fenóis via degradação redutiva por amálgama de sódio, resistência a degradação microbiana, tipos de estruturas liberadas por degradação oxidativa e pirólise, e baixo conteúdo de polissacarídeos.

Os microrganismos decompositores precisam de muita energia e , exceto em casos dos anaeróbios e quimiotróficos, as reações requerem consumo de $\mathrm{O}_{2}$ e a liberação de $\mathrm{CO}_{2}$. As taxas do primeiro aumentam e a evolução do segundo tem sido mais ou menos igualada com as taxas de decomposição da matéria orgânica e pode muitas vezes ser utilizada nos estudo deste processo. A evolução de $\mathrm{CO}_{2}$ é complicada pela solubilidade em soluções, além do que essas medidas representam a respiração total da comunidade, não distinguindo a contribuição individual de plantas ou dos microrganismos.

Em uma área de cerrado sensu stricto vários parâmetros apresentaram variação .sazonal, com exceção do teor do íon $\mathrm{SO}_{4}^{-2}$ do folhedo e do teor de $\mathrm{K}+$ do solo. Os gêneros de fungos filamentosos mais freqüentes durante o processo de decomposição desse folhedo foram: Trichoderma, Absidia, Fusarium, Cytindrocladium, Mucor e representantes do grupo Mycelia sterilia (Attili 1989).

Nesta mesma área verificou-se que a adição de vinhaça, restilo ou vinhoto no solo acarretou diminuição da velocidade de decomposição de folhas de Ocotea pulcheüa, demons- 
trando maior retenção dos elementos $\mathrm{Ca}, \mathrm{Mg}$ e diminuição dos teores de nitrogênio e proteína na fração foliar. A sazonalidade esteve presente em todos os parâmetros estudados. Verificou-se que os gêneros Trichoderma, PenicíUium, Aspergiüus e Fusarium foram freqüentes durante a sucessão fúngica no processo de decomposição dessas folhas (Schoenlein-Crusius 1988). No solo tratado com vinhaça em cultura de milho, não houve variação do número de fungos fflamentosos, mas ocorreu decréscimo do número de leveduras (Tauk 1988a). Este resíduo, entretanto, aumentou o número de bactérias e actínomicetos na mesma área (Tauk 1988b).

A velocidade de decomposição de diferentes substratos varia, sendo que a seguir estão citados alguns deles: $84 \%$ de ácido benzóico foi decomposto após 28 semanas; $81 \%$ de ácido pirúvico após 12 semanas; $26 \%$ de catecol após 28 semanas e $69 \%$ de ácido fenóüco também após 28 semanas.

As primeiras estimativas matemáticas para a decomposição de resíduos de plantas, animais e microrganismos no solo consideraram suas taxas de $\mathrm{C}: \mathrm{N}$ e o conteúdo de $\mathrm{N}$. O crescimento microbiano nos resíduos não foi considerado, devido às dificuldades encontradas para a determinação do mesmo. Existem atualmente duas tendências para descrever o processo de decomposição dos resíduos no solo. A primeira utiliza a análise de regressão da curva de decomposição e o número de grupos de indivíduos e suas taxas específicas. A segunda, procura calcular a velocidade da decomposição total dos resíduos e a formação de materiais microbiarioís.
PROPOSTAS DE ESTUDOS FUTUROS $\mathrm{Na}$ literatura encontram-se algumas das proposições de estudos futuros quanto ao processo de biodegradação:

- Mecanismos de transformação do nitrogênio orgânico para o mineral, dentro ou fora da célula. O papel das enzimas exo e intracelulares envolvidas deverá ser melhor elucidado, assim como os mecanismos de regulação $\mathrm{NH}_{4}$ e de $\mathrm{NO}_{3}{ }^{-}$.

- A eficiência de utilização do substrato e suas taxas constantes de decomposição deverão ser independentemente determinadas. Estes dois parâmetros determinam a quantidade de $\mathrm{C}$ utilizada para o crescimento microbiano, o que pode afetar a ciclagem do Ce do $\mathrm{N}$.

- Fatores que afetam as taxas de C:N dos organismos do solo.

- Controles biofísicos, tais como a reorganização estrutural e a atividade da fauna do solo, por controlarem as relações espaciais do substrato, organismos e ciclagem de nutrientes.

- Comparação de dados experimentais com modelos de simulação e maior empenho para comparação e síntese dos mesmos já existentes.

CONCLUSÃo Verifica-se que ainda resta muito a ser estudado sobre a biodegradação de resíduos orgânicos no solo, principalmente em ecossitemas tropicais, o que provavelmente contribuirá para melhor manejo da agricultura, visando efetivamente a conservação do solo.

\section{REFERÊNCIAS BIBLIOGRÁFICAS}

ATTILI, D.S. 1989. Sucessão fúngica e decomposição da fração foSar da serapilheira de cerrado no município de Corumbataí, SP. Rio Claro, SP. 183 p. (Dissertação de Mestrado, Instituto de Biociências,UNESP)

BARTHA, R. 1980. Pesticide residues in humus. ASM News. 46:356-360

CESAR, O. 1988. Composição flortstica, fttossodologia e ciclagem de nutrientes em mata mesófOa senddecídua (Fazenda Barreiro Rico, Mun. Anhembi, SP). Rio Claro, SP. 223p. (Tese de Livre Docência, Instituto de Biocièncias, UNESP).

FOSTER, R.C. 1981. Polysaccharides in soil fabrics. Sou Sci. 214:665-667.

LINHARES, L.R. \& MARTIN, J.P. 1979. Carbohydrate content of fungal humic acid-type polymers (melanins). Sou Sci. Soc. Amer. J., 43:313-318.

MARTIN, J.P. \& STOTT, D. 1981. Microbial transformations of herddides in soil. Proc. Western Soc. Weed Set., 34:39-54.

MITCHELL, MJ. \& NAKAS, J.P. 1986. Microfloral and faunal interactions in natural and agro-ecosystems. Dorcrecht. Marinus Nijhoff \& W Junk Publishers. 505p.

PAGANO, S.N. 1985. Estudo florCstíco.jitossociológico e de ciclagem de nutrientes em mata mesófila senúdeddua no municipio de Rio Claro, $S P$. Rio Claro, SP. 201p. (Tese de Livre Docência, Instituto de Biocièncias, UNESP)
SCHOENLEIN-CRUSIUS, I.H. 1988. Decomposição e sucessão de fungos de folhas de Ocotea pulshetia (Nees) Mez. em solo sob cerrado, tratado com vinhaça no municipio de Corumbatai, SP. Rio Claro, SP. 195p. (Dissertação de Mestrado, Instituto de Biocièncias, UNESP)

TAUK, S.M. 1988a. Aspectos da microbiota ffingica no solo de cultura de milho (Zea mays), tratado com vinhaça no município de Rio Claro, SP.Rtv.Microbiol., 19(3):282-289.

TAUK, S.M. 1988b. Microbiota telúrica de Latossolo Vermelho-Amarelo, com cultura de milho (Zea mays), tratado com vinhaç, no município de Rio Claro, SP. Rev. MicrobM., 19(3):229-234.
MANUSCRITO POOS Recebido em 23 de fevereiro de 1990 Revisão do autor em 02 de julho de 1990 Revisão aceita em 10 de julho de 1990 